Portland State University

PDXScholar

\title{
Social Position Influencing the Water Perception Gap Between Local Leaders and Constituents in a Socio- Hydrological System
}

\author{
Melissa Haeffner \\ Portland State University, melissahaeffner@pdx.edu \\ Douglas Jackson-Smith \\ Ohio State University - Main Campus \\ Courtney G. Flint \\ Utah State University
}

Follow this and additional works at: https://pdxscholar.library.pdx.edu/esm_fac

Part of the Fresh Water Studies Commons, Sustainability Commons, and the Water Resource Management Commons

Let us know how access to this document benefits you.

\section{Citation Details}

Haeffner, M., Jackson-Smith, D., \& Flint, C. G. (2018). Social position influencing the water perception gap between local leaders and constituents in a socio-hydrological system. Water Resources Research, 54, 663-679. https://doi.org/10.1002/ 2017WR021456

This Article is brought to you for free and open access. It has been accepted for inclusion in Environmental Science and Management Faculty Publications and Presentations by an authorized administrator of PDXScholar. Please contact us if we can make this document more accessible: pdxscholar@pdx.edu. 


\section{Water Resources Research}

\section{RESEARCH ARTICLE \\ 10.1002/2017WR021456 \\ Social Position Influencing the Water Perception Gap Between Local Leaders and Constituents in a Socio-Hydrological System}

Special Section:

Socio-hydrology: Spatial and

Temporal Dynamics of

Coupled Human-Water

Systems

Key Points:

- Constituents in Utah were concerned about future water supply and price; leaders were concerned about deteriorating water infrastructure

- Social position explained more variance in the difference between constituents and leaders than place or hydroclimatic condition

- Constituents who relied on direct mailings for information and those engaged in water boards or committees were more aligned with leaders

Supporting Information:

- Supporting Information S1

- Table S1

Correspondence to:

M. Haeffner,

melissahaeffner@pdx.edu

Citation:

Haeffner, M., Jackson-Smith, D., \& Flint, C. G. (2018). Social position influencing the water perception gap between local leaders and constituents in a socio-hydrological system. Water Resources Research, 54, 663-679. https://doi.org/10.1002/

2017WR021456

Received 6 JUL 2017

Accepted 8 JAN 2018

Accepted article online 11 JAN 2018

Published online 1 FEB 2018

(C) 2018. American Geophysical Union. All Rights Reserved.

\author{
Melissa Haeffner ${ }^{1 D}$, Douglas Jackson-Smith², and Courtney G Flint ${ }^{3}$ \\ ${ }^{1}$ Department of Environmental Science and Management, Portland State University, Portland, OR, USA, ${ }^{2}$ School of \\ Environment and Natural Resources, The Ohio State University, Columbus, OH, USA, ${ }^{3}$ Natural Resource Sociology, \\ Department of Sociology, Social Work and Anthropology, Utah State University, Logan, UT, USA
}

\begin{abstract}
How well city leaders represent their constituents and meet their needs are key concerns in transitioning to local sustainable water governance. To date, however, there is little research documenting the influence of social position between elected leaders who make policy, career staff water managers who design and operate systems and implement policies, and the members of the public whose individual water use behaviors are important drivers of water sustainability outcomes. In this study, we ask: "How does social position explain variation in water perceptions and concerns between different actors in a sociohydrological system?" Using a mixed method approach with survey and interview data, we explore the ways that positioning within the governance system, geographic context, and citizen engagement in local government mediate perceptions of the urban water system. Regardless of local biophysical water supply conditions, residents showed most concern about future water shortages and high water costs, while their leaders were consistently most concerned about deteriorating local water infrastructure. Further, constituents who received water-related information directly from public utility mailings or served on community committees and boards had perceptions that were more aligned with leaders' concerns. The importance of social structure over natural and built environments in shaping water issue perceptions underscores the value of social analysis in socio-hydrology studies. Further, practitioners looking to increase consensus for a transition to sustainable water governance might work to develop institutional mechanisms to increase opportunities for water user involvement in local water system governance.
\end{abstract}

Plain Language Summary Do city leaders differ from the public on key water issues, and if so, why? We use surveys and interviews with urban Utah Mayors, City Council persons, public utilities staff, and residents to compare their concerns about the current and future water supply, water shortages, quality, cost, and infrastructure. We find that residents were more concerned about future water shortages and high water costs, while leaders were more concerned about deteriorating water infrastructure. This was the case no matter where cities were located or what their water source was. Leaders also thought that their relationship with their publics was largely reactive. The results suggest that socio-hydrology models that presume that actors in the social structure are equally and fully informed of the issues or would respond to cues in the same way may lead to oversimplified results. Where misaligned expectations between leaders and constituents result in unintended consequences, a greater attention to the values, norms, and attitudes held by different actors with different roles serves both policymakers as well as socio-hydrological modelers.

\section{Introduction}

Addressing future water challenges requires interdisciplinary investigation into the interactions and feedbacks between social systems and water resources. Exposure to changing environmental conditions and shifts in societal values and preferences can have real consequences on the evolution of water management policies, water system infrastructure, and hydrologic outcomes. The study of socio-hydrology has emerged as a promising way to understand the dynamic coupling of human, built, and biophysical components of hydrologic systems (Sivapalan et al., 2012).

To date, much of the work in socio-hydrology has treated aggregations of individual water user behaviors as proxies for the "management response" to an environmental stimulus, or assumed that these can occur 
without significant mediation by local water management institutions (e.g., Elshafei et al., 2014). Other models have explicitly represented the role of government actors, but expect community resident experiences and sensitivities to translate into responsive actions by local water system policymakers and managers in a relatively straightforward manner (Chen et al., 2016; di Baldassarre et al., 2013). However, extensive research on the dynamics of power and decision-making in local government, particularly around natural resource issues, suggests that linkages between community resident needs and desires and the behaviors of local leaders and resource managers are likely to be more complex (Sherren et al., 2017). Social systems typically include actors with widely different levels of decision-making power and influence, and it is rare that the experiences and concerns of rank-and-file citizens directly translate into decisions by local or regional public and private governance organizations (Logan et al., 1997; Moss \& Newig, 2010).

In this paper, we use primary data from a study of urban water systems in Northern Utah, USA to explore the connections and feedbacks between the perceptions and concerns of water system governance actors and water users. We use quantitative survey and qualitative interview data to explore social position between these different actors as well as the spatiality between communities in different hydroclimates and stages of urban development. Our results highlight the disconnections between water users and water governance actors, and illustrate how historical and current events can shape water system management decisions in socio-hydrological systems. We conclude by pointing to implications for the conceptualization and operationalization of citizen-leader feedbacks in coupled system models.

\subsection{Socio-Hydrological Frameworks}

Traditional hydrology studies that focus solely on natural processes such as water quality have been criticized as neglecting key social mechanisms that shape hydrologic outcomes and can cause systems to shift (Chen et al., 2016). Socio-hydrology frameworks have been developed to address this problem by recognizing the importance of "the meaning and value of water as a culturally, politically, and economically embodied resource" (Sivapalan et al., 2014). Innovative applications of socio-hydrology frameworks link key components of the social, natural, and built environments to generate hypotheses and explore dynamics affecting water quality and quantity outcomes (Pande \& Sivapalan, 2017). For example, efforts to reduce nuisance flooding can alter public awareness of flood risks and negatively impact a community's adaptive capacity for resilience (Yu et al., 2017).

To date, social science contributions to the socio-hydrology literature have focused on the development of conceptual models that capture how human actors perceive and respond to changes in environmental conditions (di Baldassarre et al., 2013), and there is growing attention to the importance of institutions and social norms as key mediating forces in this process (Chen et al., 2016; Yu et al., 2017). The dominant approach to representing the "social" components and feedback loops within coupled socio-hydrology models has been to use behavioral equations that operationalize key social science concepts in a systematic and theoretically consistent framework (Elshafei et al., 2014). These equations are often based on social theories about rational actors and represent examples of what Sivapalan et al. (2012) call "process sociohydrology." Others have relied more on comparative case studies or historical studies to highlight the role of broader social forces in shaping the evolution of catchment hydrology across time and space (Chang et al., 2014; Liu et al., 2014). Results of these case studies are often used to parameterize process equations in coupled models.

As noted above, the linkages between individual water user (or community resident) experiences and responses by local governance institutions are complex. In the United States' context, local municipal governments are active in making water resource investments and policy decisions that shape patterns of water use and constrain responses to social, economic, and environmental stressors (Hess et al., 2016; Munger \& Houghton, 1965; Treuer et al., 2017). Because they are large enough to garner investment funds and have authority over a number of sectors, municipal political jurisdictions are uniquely positioned to design and implement effective solutions (Betsill \& Bulkeley, 2006). At the same time, they are small enough to be familiar and interact with active publics and can accumulate local knowledge that can lead to adaptive management decisions and technological innovations specific to their geography, climate, and culture. They can also work on a faster time scale than many larger agencies and can establish enterprise funds from the sale of water to plan infrastructure improvements. Local leaders do respond to and communicate with their publics about a host of water issues, creating a social dynamic that influences the direction of 
change within socio-hydrological systems. Decisions are also shaped by the historical development of urban water infrastructure and policies, which themselves are shaped by local hydrologic conditions, population growth, and critical water system crises or events (Chang et al., 2014; Head, 2014).

There have been previous empirical studies on leaders' water perceptions (Coppock \& Brown, 2007; O'Connor et al., 2005), the public's perceptions of various water issues (Canter et al., 1993; de França Doria, 2010; Flint et al., 2017; Po et al., 2003), and gaps between expert and layperson values on other types of environmental issues (Anderson \& Theodori, 2009; Crowe et al., 2015; Lazo et al., 2000; Sjoberg, 1999). In the analysis below, we extend this work to explore perceptions and concerns about water issues between community residents and their water system leaders and managers. Specifically, we seek to identify linkages between different sets of actors in urban water governance systems and possible biophysical factors that may indirectly influence water issue perception over time.

Our work is guided by a conceptual model that was specifically designed to capture important feedbacks between social, built, and natural features of urban water systems in Northern Utah, and to facilitate communication among scientists from diverse disciplines working on a collaborative research project (Hale et al., 2015). The integrated Structure, Actors, and Water (iSAW) framework was designed to identify relationships among key elements of the water system to enable analysis of diverse water resource issues (e.g., water quality, water quantity) and at different scales (e.g., plot, city, catchment, or region). The iSAW framework identifies three key components of any coupled water system: Structure, Actors, and Water. The present paper magnifies the Actor component and its link to Structural attributes of the water system. Specifically, we are curious about how the perceptions, information, and experiences of water system conditions may differ between individual and organizational actors, and the ways that interactions between these two categories of actors facilitate or constrain movement toward more sustainable water management (Figure 1).

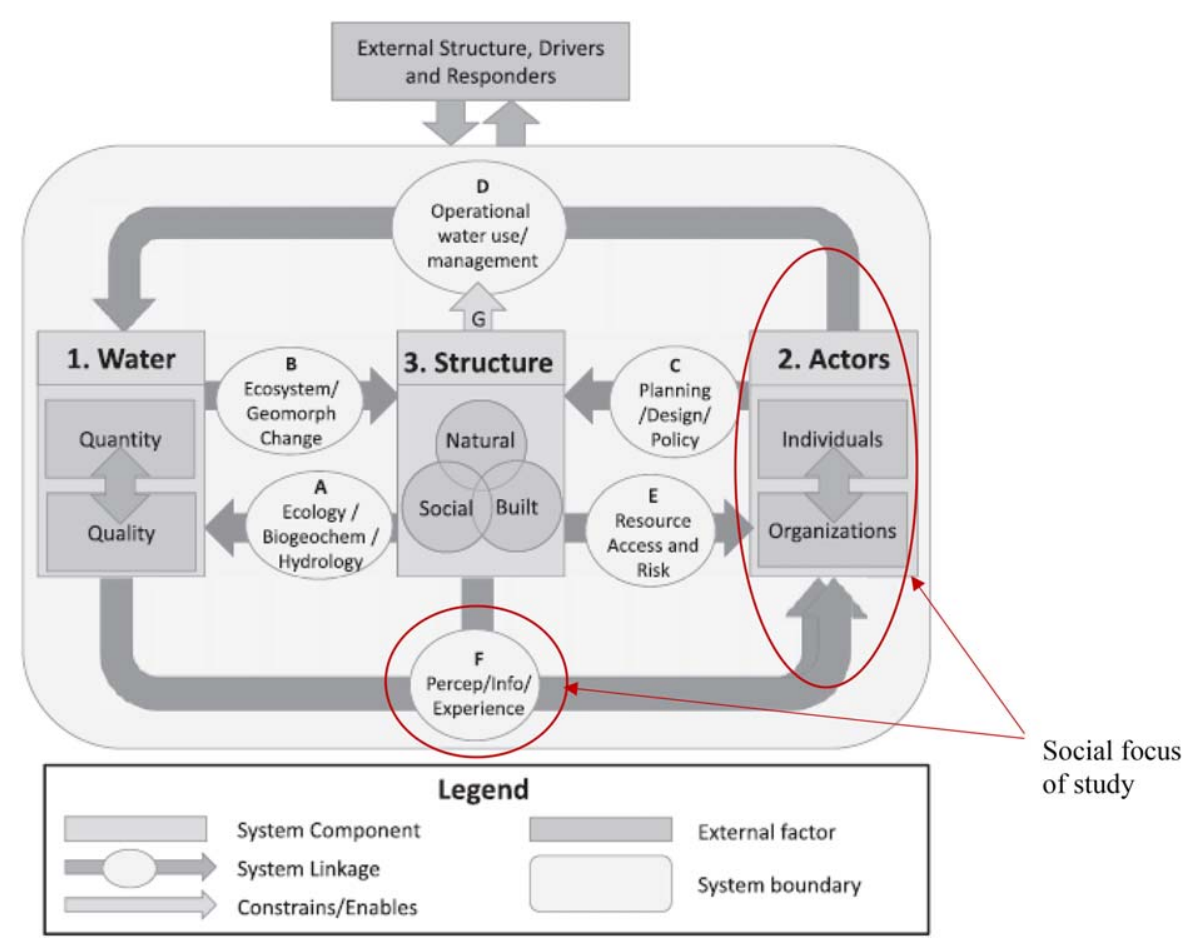

Figure 1. The iSAW conceptual framework is a socio-hydrological framework, which organizes seven key linkages (arrows) between three main components: water, actors, and structure (gray boxes; Hale et al., 2015). The system boundary (light gray shaded box) separates internal and external (box with dark shading) components. Red circles focus attention on the component (Actors) and system link (PIE: Percep/Info/Experience) central to the present study on social position of local water governance. 
A central component of the iSAW framework is the idea that actor perceptions and experiences of water quality and quantity conditions are not only shaped by the built and natural structures that define biophysical processes within all water systems but are also mediated by the larger social structure. As noted above, all socio-hydrologic conceptual frameworks include representation of key human actors (typically farmers, land owners, water users, or industries) and are distinctive in the ways they link the behaviors of these actors to changes in the water system and other socioeconomic conditions (cf., Elshafei et al., 2014). Most published frameworks also assume a relatively simple (unmediated) relationship between objective physical states of the water system and subjective perceptions, experience, and information (PIE) of these actors. In other words, they presume that as environmental conditions change, actors throughout the system will have roughly equal chances of experiencing, perceiving, and responding to these changes.

The iSAW model provides a conceptual basis for unpacking the ways in which different actors' PIE will be shaped by attributes of their biophysical setting (e.g., precipitation, topography, soils), previous investments in built water infrastructure (e.g., reliance on surface versus groundwater sources for culinary water), and social structure (e.g., community norms, gender roles, class, or occupational stratification).

For the present analysis, we are interested in how perceptions, experience, and information about an urban water system differ depending on an actor's social position, or whether one is an individual water user or a leader of water system governance organizations. Because human behaviors and responses to environmental signals are key drivers of sustainability transitions, their perceptions, information, and experience are important in shaping how actors respond. Roles and social experience expose actors to different kinds of information and lead to different priorities and worldviews. Indeed, people living in different places experience distinctive events that shape how they prepare for and respond to future events. Lessons from around the world have demonstrated, for example, that the evolution of urban water infrastructure is largely the result of a history of social interactions with the water cycle including natural resource accumulation, shifts in material and ideological practices, and impacts on traditional cultural practices and social relations between different water users (Haeffner et al., 2016; Head, 2014). The physical location of actors, especially municipalities, also influences their exposure to episodes of water shortage, impacts of water infrastructure decisions (or indecisions), and vulnerability to climate change. In these ways, decisions by individuals and organizational actors about how to use water (and whether to change how local governance operates) are shaped by social structures (e.g., laws, policies, social divisions), natural structures (e.g., available water sources, weather), and the built environment (e.g., urban size, water distribution systems).

\subsection{Constituents as Water Actors}

Understanding the role of individuals in a community is an important element in water sustainability transitions, for example, as citizens who are more or less politically exposed to environmental awareness who may advocate for change (Hughes et al., 2013). The presence of informed and engaged communities is posited to lead to more direct democracy and just water sustainability (Rinaudo \& Garin, 2005; Susskind, 2013, p. 666) as articulated in this recommendation:

Before intractable conflicts emerge, elected, and appointed leaders should involve water users in generating water resource management policies and plans. In return, water users or stakeholders must accept shared responsibility for inventing ways to meet the conflicting interests of multiple groups at the same time, given legal, financial, and other constraints. (Susskind, 2013, p. 675)

In addition to engagement, exposure to different kinds of water-related information can also shape constituents' ability to contribute to sustainable water system management (Treuer et al., 2017). End users of water interact with both natural and cultural environments and receive cues about water system issues through their activities-indoor and outdoor water use, landscaping, deciding whether or not to move to waterscarce or water-rich areas, paying or not paying water bills, attending public meetings, and the like (Canter et al., 1993; de França Doria, 2010). Participating in these activities shapes perceptions of water use, allocation, and management (Endter-Wada et al., 2009). Yet residents are not uniform in their perceptions or concerns. In fact, Flint et al. (2017) found that while female, older, nonwhite, and recreationally active respondents in northern Utah tended to be more concerned about water issues, these trends varied significantly across geographic regions. 
We expect that communities in different locations will experience different biophysical conditions (e.g., dependency on ground versus surface water), different built environments (e.g., water infrastructure), and different social structures (e.g., access to different sources of information or mechanisms for engagement), and that these differences will lead to variation in water perceptions and concerns. Indeed, if members in a similar community collectively experience threats to persons, property, or values (as might be the case with water quality deterioration or water-related disaster), this can create a sense of solidarity (Fitchen et al., 1987; Flint \& Luloff, 2005, p. 406). They might identify with a shared sense of risk that can be measured both in how similar peoples' perceptions are to each other and in how different they are from those outside of the community. This collective expression of concern, or community risk perception, (Flint \& Luloff, 2005) suggests that the collective might have a heightened sense of concern for issues they identify with as "risky" as opposed to other issues with which they do not identify. Perceptions shared and acted upon within communities reflect past interactions between governance actors and citizens in response to changing water-related conditions and events. Better understanding the built, natural, and social factors underlying concerns and perceptions may lead to tailored policies and communication that promote adaptation and mitigation (Flint \& Luloff, 2005, p. 408, Paveglio et al., 2016).

\subsection{Leaders as Water Actors}

In a study of 22 cities in the southwest United States, local leader preferences were found to drive decisionmaking more than partisan differences (Hess et al., 2016). In two eastern states in the United States, (O'Connor et al., 2005) water manager decision-making was influenced by how much they felt at risk to weather emergencies (e.g., flooding), underscoring the need to assess water concerns and perceptions. Another study of water leaders in Melbourne, Australia revealed that leaders made decisions at least partially due to their perceptions about the social and political acceptability of alternative solutions (Coppock \& Brown, 2007). Studies also tend to find differences in concern between field experts and laypersons. For example, using viewpoint analysis, Rinaudo and Garin (2005) identified variance in levels of concern between water stakeholders and experts in France, where professionals tended to be influenced more by their technical background than individual water users. A study in Sweden found that differences in layperson and expert opinion on the environmental risks of nuclear waste could be traced to public distrust of elected officials (Sjoberg, 1999). Accounting for discrepencies between leader and constituent perceptions can provide valuable information about the evolution of governance arrangements in complex socio-hydrologic systems.

In the analysis below, we focus on two broad categories of urban leaders relevant to water governanceelected officials and water utility managers. Our work focuses on the social position within water governance at the city level in the United States, where voters typically elect leaders to make funding and policy decisions about the provision of municipal services, including the development of local water system built infrastructure, water pricing policies, land-use and building ordinances, and water conservation programs. City water system managers (usually career staff) are the actors who operate these systems, develop and maintain the built infrastructure, bill water users, manage customer complaints, and ensure compliance with state and federal environmental, health, and safety laws.

\section{Research Questions}

We explore the importance of social roles, place, and user characteristics under the overarching theme of "What explains variation in water perceptions and concerns between different actors in a socio-hydrological system?" Following Chang et al. (2014), we ask a set of subresearch questions to explore both direct and intentional and indirect and unintentional pathways between leader and constituent perceptions, information, and experience on water issues.

1. To what extent do the different roles that leaders, managers, and water users play in the urban water system explain variation in their water perceptions and concerns in a socio-hydrological system?

2. To what extent do differences in the built and natural environment explain variation in water perceptions and concerns across cities?

3. To what extent do perceptions of water system issues vary when cast at local versus state scales?

4. To what extent does the way in which individual water users receive information and engage in local governance institutions explain variation in their perceptions and concerns about water? 
5. What kinds of information exchange and engagement with their constituents are reported by water system leaders, and does this vary by place or the ways in which the built environment has evolved over time?

Question (1) lays the groundwork by exploring differences between different actors in urban water governance. If differences are absent, we expect that the potential for conflict or maladaptation to environmental pressures is reduced, but if present, we hypothesize that the potential for blocking action might be heightened. Questions (2) and (3) examine indirect and unintentional pathways between different actors in water governance based on place and scale. If present, we hypothesize that perception differences are dependent on complex externalities and may be a result of other interactions in the coupled human-nature system such as difference in climate or hydrology. Questions (4) and (5) examine direct and intentional pathways between leaders and constituents. If these pathways are present, we hypothesize a "straightforward coupling," (Chang et al., 2014), whereby the quality of leader-constituent interaction matters for water governance and urban water policy. To capture the multiple pathways in which leaders and constituents influence each other, and expose areas where the potential for conflict might exist, we examine (1) the relationship between different types of leaders and constituents, (2) the quality of the interactions between leaders and constituents over time, and (3) possible impact of location and scale on perception.

\section{Methodology and Data Collection}

This research project was designed to capture social position within urban water systems in urban Utah. To explore the importance of built, natural, and social structure, we selected a set of urban residential neighborhoods that represent a diverse range of land use, land cover, built environment, household structures, residential properties, socio-demographic attributes, water infrastructure, climate characteristics, and policy contexts (Jackson-Smith et al., 2016b). The research design included neighborhoods, cities, and valleys at different stages in the evolution of urban water systems in this region, which can provide insights into the coupled aspects of social, institutional, and hydrologic aspects of urban water systems. We also gathered historical information through secondary data and qualitative interviews, and used these to identify ways that legacies of natural resource use and cycles of decision-making between leaders and constituents in our study communities have contributed to the socio-hydrological patterns, we observe today.

\subsection{Study Area}

We chose a water-stressed region in the United States and selected cases that represented different stages of urban development with varying socio-demographic patterns and different hydroclimates. The Wasatch Range Metropolitan Area (WRMA) is a large metropolitan region in Northern Utah that includes cities and valleys with distinctive demographic, economic, and cultural characteristics, and which have distinctive built and governance systems to manage water for both farm and urban use, creating different hydrosystems (Jackson-Smith et al., 2016b).

We chose three valleys in the region to study: Salt Lake Valley (SLV), Heber Valley (HV), and Cache Valley (CV), which account for $42 \%$ of Utah's total population. SLV is home to the state's capital and largest city (Salt Lake City), approximately $20 \%$ of the state's residents, and has by far the largest and most diverse population in terms of income, race/ethnicity, religious identity, and political orientations. Meanwhile, HV and CV are less dense in population and tend to be more agricultural with no cities greater than 50,000 in population (Flint et al., 2017). CV's population is notably younger with a lower median household income and higher poverty rate. $\mathrm{HV}$, in contrast, is a popular amenity destination and marked by a large proportion of seasonally occupied residences and has the highest median household income among the study sites. CV and HV land use is dominated by agriculture ( $80 \%$ and $54 \%$, respectively) while SLV has mostly converted from farming to urban and commercial land uses (Flint et al., 2017). Rates of population change between 2000 and 2010 were higher in CV and HV (23\% and 55\%, respectively) than SLV (15\%). CV and HV residents tend to have a more conservative political voting pattern than Salt Lake (Flint et al., 2017).

Within these three valleys, we selected 23 neighborhoods in 11 cities using a three-stage clustering approach for more intensive study. These cities and neighborhoods represent a range of population sizes, built water systems, and political orientations (Jackson-Smith et al., 2016a). 


\subsection{Hydrological Characteristics}

Because of their larger population density and built infrastructure, cities in SLV depend primarily on surface water runoff from mountain snowmelt for drinking water supplies (Maupin et al., 2014), while HV and CV municipalities depend nearly exclusively on groundwater. In 2010, Salt Lake County public water systems supplied 1,027,470 people with $72 \mathrm{Mgal} / \mathrm{d}$ drawn from groundwater and $224 \mathrm{Mgal} / \mathrm{d}$ (76\%) from surface water (United States Geological Survey (USGS), 2010). Cache County public systems supplied 107,580 residents using $33 \mathrm{Mgal} / \mathrm{d}$ from groundwater and $0.4 \mathrm{Mgal} / \mathrm{d}$ from surface water (USGS, 2010). HV is located in Wasatch County, where public water systems served 22,485 people using $8 \mathrm{Mgal} / \mathrm{d}$ from groundwater and $0.1 \mathrm{Mgal} / \mathrm{d}$ from surface water (USGS, 2010). The estimated public supply per capita uses in gallons/person/ day are 288, 311, and 371, respectively (USGS, 2010). One of our study cities in the SLV switched their primary water source in 2014 from groundwater to surface water to address public concerns about water quality in local groundwater (this occurred during our data collection effort, after the household survey and before the iPad surveys and interviews discussed in section 3.3).

\subsection{Survey Data Collection}

Two survey efforts were conducted as part of the iUTAH (innovative Urban Transitions and Aridregion Hydro-sustainability) project (www.iutahepscor.org) for the purpose of collecting resident perceptions and concerns about the socio-hydrological system of the Wasatch Range Metropolitan Area, Utah.

\subsubsection{Household Survey}

A door-to-door household survey was administered in the summer of 2014 to over 4,000 housing units across the study area to assess local resident perspectives on water issues in the selected valleys (JacksonSmith \& Flint, 2016). Within each of 23 selected neighborhoods across the 11 cities, households were randomly sampled from county and city property tax rolls. The survey was administered using a dropoff/pickup methodology and achieved a response rate of $62 \%$ with 2,343 completed surveys $(2,108$ usable for this study; Jackson-Smith et al., 2016a). An average of 3.3 visits were made to each sampled housing unit (median $=2$ ) and 2.8 attempts were made to pick up surveys at households where a dropoff had occurred (median $=2$ ). Mail back options were included for unsuccessful pickups and unsuccessful dropoffs, and surveys were mailed to housing units, where access to a door was not possible (e.g., gated communities) using a standard 5-wave approach. No replacements were made for ineligible housing units (e.g., businesses or vacant units) (see Jackson-Smith et al., 2016a, for complete details). Household survey respondents were found to be representative of the larger population within each study neighborhood by comparing results to Census data (Endter-Wada et al., 2015).

Two sets of questions in the survey measured household water supply perceptions, with distinct responses captured at each of three different geographic scales: "Is there enough water to meet the CURRENT needs of all the people and businesses in (your city/this valley/Utah)?" and "Is there enough water to meet the FUTURE needs of all the people and businesses in (your city/this valley/Utah)?" Answers were coded using a Likert scale that ranged from Strongly disagree (1) to Neither (3) to Strongly agree (5). A separate battery of questions asked "Thinking about the next 10 years in [Your Valley], how concerned are you about the following issues?" with answers for each of 10 items captured using a 5-point scale that ranged from "Not at all concerned" (1) to "Very concerned" (5). In this paper, we focus on responses to four water-related topics included in that question: water shortages, the high cost of water, deteriorating water infrastructure, and poor water quality.

Another question asked respondents "Do you get information about water issues from any of the following sources?" Options included: any newspaper, TV or radio, Internet or social media, mailings or another contact from water provider, and conversations with friends and neighbors. To determine how households engage in their communities, the survey asked: "Have you or any adult in your household participated in any of the following activities during the past 12 months?" Respondents checked "yes" or "no" for each of the following options: civic or charity group activities, contacted a public official about some issue, attended a public meeting or hearing, worked with others on an issue or problem in my community, and served on a government board, committee, or commission.

\subsection{2. iPad Survey Data Collection}

The Utah Water Survey (UWS) was conducted across all major urban areas in Utah between 2014 and 2016 by asking randomly selected adults shopping at 31 grocery stores to complete a brief survey using handheld iPads (Jackson-Smith \& Flint, 2017). Stores were selected to reflect a broad range of geographic 
locations and store characteristics found in the urban areas across the state. Shoppers were approached using a protocol that required field staff to approach the next adult to cross a designated line in front of the store whenever their iPad was available. Of roughly 35,000 adults observed entering a store, 18,908 shoppers (54\%) were invited to complete a survey. Of these, 926 were disqualified for being under 18 or because they were not Utah residents. Overall, $41 \%$ of eligible adults approached agreed to complete a survey, providing a total usable sample of 7,364. To test for possible response bias, we compared the gender profile of the shopping population and the respondent pool, which appeared to be consistent $(55.2 \%$ female versus $53.2 \%$ female, respectively).

Respondents were asked nearly identical questions about water perceptions and concerns as used in the household survey described above. First, perceptions of water shortages were captured by asking for levels of agreement with two statements: "There is enough water to meet the CURRENT (or FUTURE) needs of all the people and businesses in my community." Answers were coded using the same 5-point scale. Additionally, respondents were asked an identical question block that rated concerns about 10 issues (including four key water topics). Respondents also reported the zip code of the place where they live, and we used these zip codes to identify the subset of iPad survey responses that came from residents of the 11 cities included in this study (which produced a total useable sample of 2,234). Results from the full statewide sample from the survey can be viewed in an online, interactive visualization tool (Jones et al., 2016).

\subsection{Interview and Survey Data Collection With Local Leaders and Water Managers}

Our study also uses results from face-to-face interviews with 41 water governance actors in the 11 study cities. Specifically, we interviewed a total of 24 elected officials (mayors, city council members, etc.) and 17 water managers (e.g., public utilities or public works directors). Participants were sought who represented diverse types of cities in each of the three study valleys. In smaller cities where staff plays multiple roles, those who performed at least some operations in water management were selected. Those selected for interviews were identified through city websites and, in a few cases, via phone calls to city hall. Participants were first contacted by email with follow-up calls by telephone as needed.

All of the interviews were conducted in-person between November 2015 and July 2016. Among other topics, all respondents were asked: (a) What is your role and responsibilities around water in this position and how long have you been working for this city?; (b) What is the number one key water issue facing your city today?; (c) Does your city have an adequate water supply to meet the city's needs today?; (d) Does your city have an adequate water supply to meet the city's needs in the future?; (e) What is your opinion on water quality in terms of drinking water and in terms of waterways?; ( $f$ ) Are there any water hazards that impact your city?; and (g) What sorts of things do you think are important for water conservation? Respondents were encouraged to discuss times of conflict or consensus with their constituents if they thought their constituents were actively engaged in water issues, and how they interacted with constituents. In addition to a semistructured interview, all participants were asked to fill out the same iPad survey used in the Utah Water Survey.

During this study period, city elections complicated contacting and identifying key informants. When able, we interviewed the incumbents. Only one potential respondent who had initially agreed to an interview canceled without follow-up, for a response rate of $97.6 \%$. One interview was discarded because the respondent did not fit the study criteria.

Interviews were audio-recorded and lasted between 20 and 90 min. Each interview was transcribed and independently coded for themes by three researchers using NVIVO 11 Pro. Using a deductive approach, the team started with an a priori coding matrix based on the water concern issues listed in the surveys while inductively allowing for additional themes to emerge through the revision of categories and the coding agenda, reaching intercoder reliability (>80\% kappa coefficient; see Online Resources for codebook, nodes, and subnodes).

\section{Mixed Method Approach and Analysis}

\subsection{Mixed Method Approach}

Mixed methods in data collection and analysis can solve scale problems by filling in gaps left by individual methods. Our approach parallels other recent studies of transitions in water regimes that combine 
quantitative (e.g., statistically analyzed survey data) and qualitative (e.g., thematically coded interview data) methods (Hess et al., 2016; Treuer et al., 2017). Combining the three data sets enables us to triangulate information from multiple sources of data. For example, interviews with water system leaders provide one perspective on how engaged constituents are in water decisions, while household survey data provide insights from the perspective of local residents. Because it could be completed in a few minutes, the iPad survey instrument enabled us to captured perceptions of a broad swath of the public in each city, but provided much less detail about household characteristics, perceptions, and activities than the 16 page household survey. By comparing the results from these three data sets, we can be more confident in the validity and reliability of our results (Denzin \& Lincoln, 2011; Johnson et al., 2007; Klandermans \& Staggenborg, 2002).

\subsection{Analysis}

We first explored the degree to which perceptions and concerns about water vary according to the roles that actors play in a socio-hydrological system. This is accomplished by comparing whether answers to survey questions about water perceptions and concerns by leaders (iPad survey) and constituents (both iPad and household surveys) were aligned or not. Two statistical tests-an independent samples $t$ test (for bivariate comparisons) and an ANOVA difference in means test (for comparisons across multiple groups)—were computed for the survey data sets using SPSS V 24. Initially, we looked at differences between responses of leaders and constituents, and between those of elected officials and city water managers. We then analyzed the qualitative interview data with the leaders to explore the different ways in which elected officials and water managers are connected to their constituents.

Second, we explored how characteristics of place-the hydrologic and built structure-influences perceptions and concerns about water issues. To assess the degree to which locational context might influence differences in how water issues are perceived, we separated survey respondents into groups based on whether their city is principally surface or groundwater-dependent and used independent samples $t$ tests to look for statistically meaningful differences. We also compared responses between residents of each of the three study valleys to identify which themes appear to be region-wide issues and which appear to be local. In all cases, we used results from our qualitative interviews to help explain statistical patterns in the survey data, and to improve our understanding of the historical processes leading up to distinctive approaches to water management in each of our study locations.

Finally, we explored how patterns of community engagement and use of information sources affect citizen perceptions and concerns about water issues. Specifically, we compared responses from different subsets of household survey respondents (engaged/nonengaged, and information source use/nonuse), and to the iPad survey responses from the interviewed municipal leaders. We then used the interview transcripts to elaborate on how elected officials and water managers in different valleys engage with their constituents about water issues and perceive their constituents' levels of engagement on these issues.

\section{Results}

\subsection{Roles}

Comparing the responses to similar questions between local water system leaders and their residents, we find striking differences in the way in which leaders and the lay public think about water issues. In both the iPad and household surveys, the issues of shortages and high costs are the most serious water concerns of the general public. Leaders are more likely than their citizenships to agree that the city's water supply is adequate to meet the needs of their community (Table 1). Leaders also tend to be less concerned about water shortages, the high cost of water, and water quality in the next 10 years but more concerned than residents about deteriorating water infrastructure.

The qualitative interviews confirmed that the primary concerns of leaders revolve around water system infrastructure-maintaining it, building it, and funding it-and this is true across all three valleys. One elected official from SLV explained: "We have some water delivery in the city that is still done through wooden pipes that are over one hundred years old." A water manager in HV noted: "Ideally, we would like to be in a position to put in a pressurized irrigation system and eliminate the open ditches, to put in curb, and gutter to handle stormwater, but it's just the budgetary challenge that we have not yet dealt with." Not 
Table 1

Mean resident Perceptions and Water Concerns

\begin{tabular}{|c|c|c|c|c|c|c|}
\hline \multirow[b]{3}{*}{ \# cases } & \multicolumn{3}{|c|}{ Residents } & & & \\
\hline & \multirow{2}{*}{$\begin{array}{c}\text { A } \\
\text { Leaders } \\
41\end{array}$} & \multirow{2}{*}{$\begin{array}{c}\begin{array}{c}\text { B } \\
\mathrm{HH} \text { Srv }\end{array} \\
2,108\end{array}$} & \multirow{2}{*}{$\begin{array}{c}\underset{C}{C} \text { iPad } \\
2,234\end{array}$} & \multicolumn{3}{|c|}{$\begin{array}{l}\text { Independent } t \text { test for } \\
\text { significant difference }\end{array}$} \\
\hline & & & & $A \vee B$ & $A \vee C$ & $B \vee C$ \\
\hline \multicolumn{7}{|l|}{ Perception that water supply is adequate } \\
\hline CURRENT & 4.22 & 3.30 & 2.89 & $* * *$ & $* * *$ & $* * *$ \\
\hline FUTURE & 3.02 & 2.64 & 2.20 & * & *** & *** \\
\hline \multicolumn{7}{|c|}{ Concern about issue over next 10 years in community } \\
\hline Deteriorating water infrastructure & 4.10 & 3.68 & 3.70 & * & * & n.s. \\
\hline Water shortages & 3.32 & 3.72 & 4.06 & * & *** & $* * *$ \\
\hline High cost of water & 3.17 & 3.93 & 3.72 & $* * *$ & $* * *$ & $* * *$ \\
\hline Poor water quality & 2.61 & 3.53 & 3.53 & $* * *$ & **** & n.s. \\
\hline
\end{tabular}

Note. Significance test results denoted as: ${ }^{* * *} p<0.001$; ${ }^{* *} p<0.01 ;{ }^{*} p<0.05 ;$ n.s. $=$ not significant. HH Srv, household survey; iPad, iPad survey.

only did leaders spend more time talking about infrastructure than any other topic in the interviews, but $22 \%$ also listed it as the number one issue facing their city today, more than any other issue.

We found few differences in water perceptions and concerns between the elected officials and city managers in their survey responses, with two exceptions: perceptions of future water supply and concerns about the high cost of water. Water managers were more likely to agree that the future water supply is adequate than elected officials (mean 3.41 versus 2.71 , respectively, $p=0.046$ ). Meanwhile, elected officials were more concerned about the high cost of water than water system managers (mean 3.54 versus 2.76, respectively, $p=0.035$ ).

There were also a few statistically significant differences between the responses of residents who were included in the household survey, and those who replied to the iPad surveys. Specifically, the household survey respondents were more likely to see the water supply in their community as adequate and were less concerned about water shortages (though they were more concerned about the high cost of water). It is worth noting that the household survey respondents were representative of adult residents living in the study neighborhoods within each city, but not necessarily of the entire city resident population. In most cities, we only sampled one neighborhood. Meanwhile, the iPad respondents likely represent a broader crosssection of each city's population, but the data set provided less detailed information about household characteristics.

\subsection{Place}

To explore how geographic context might affect water perceptions and concerns, and the "gap" between leaders and constituents, we break the results down by valley in Table 2. SLV residents were consistently more pessimistic about both their community's current and future water supply than residents in the other two valleys. Perceptions of water supply were not significantly different between survey respondents in HV and CV. In all three valleys, residents were more pessimistic about water supply adequacy than their leaders. While not reaching the level of statistical significance, perhaps associated with the relatively small sample size for the leader iPad survey, the average scores suggest that leaders in the SLV communities (which rely principally on surface water sources for their drinking water supplies) were somewhat more likely than leaders in HV and CV (which rely on groundwater) to agree that their current water supply is adequate, but less likely to agree that their future supplies would be adequate. Concerns about water issues among water system leaders do not differ significantly across valleys, implying that spatiality might not be as important as other drivers. The top concern of water leaders in each of the valleys was deteriorating water infrastructure, and were quantitatively (but not significantly) higher in CV and HV than SLV.

Table 2 reveals that SLV residents and leaders expressed higher levels of concern about poor water quality than their counterparts in the other two valleys. On the one hand, there could be spatial dynamics at play - the Jordan River that runs through many of the SLV cities is listed as an impaired waterway on the state's 303(d) list (Utah Department of Environmental Quality, 2016). But recent events also played a role in 


\section{CAGU Water Resources Research}

Table 2

Perception and Concern About Water Issues by Valley and Source of Data

\begin{tabular}{|c|c|c|c|c|c|c|c|c|c|c|c|c|c|c|c|}
\hline & \multicolumn{8}{|c|}{ Mean scores } & \multicolumn{7}{|c|}{ Valley differences ${ }^{1}$} \\
\hline & \multicolumn{3}{|c|}{$\begin{array}{c}\text { SL valley } \\
\text { (SW } \\
\text { dependent) }\end{array}$} & \multicolumn{3}{|c|}{$\begin{array}{c}\text { Cache valley } \\
\text { (GW } \\
\text { dependent) }\end{array}$} & \multicolumn{2}{|c|}{$\begin{array}{l}\text { Heber valley } \\
\text { (GW } \\
\text { dependent) }\end{array}$} & \multicolumn{3}{|c|}{ SL v CV } & \multicolumn{2}{|c|}{ SL v HV } & \multicolumn{2}{|c|}{$\mathrm{CV} \vee \mathrm{HV}$} \\
\hline & Leaders & $\begin{array}{c}\mathrm{HH} \\
\text { survey }\end{array}$ & iPad & Leaders & $\begin{array}{c}\mathrm{HH} \\
\text { survey }\end{array}$ & iPad & Leaders & $\begin{array}{c}\mathrm{HH} \\
\text { survey }\end{array}$ & Leaders & $\begin{array}{c}\mathrm{HH} \\
\text { survey }\end{array}$ & iPad & Leaders & $\begin{array}{c}\mathrm{HH} \\
\text { survey }\end{array}$ & Leaders & $\begin{array}{c}\mathrm{HH} \\
\text { survey }\end{array}$ \\
\hline \# cases & 21 & 924 & 1,617 & 14 & 877 & 604 & 6 & 307 & & & & & & & \\
\hline \multicolumn{16}{|l|}{$\begin{array}{l}\text { Perception that water } \\
\text { supply is adequate }\end{array}$} \\
\hline CURRENT & 4.57 & 3.17 & 2.81 & 3.93 & 3.39 & 3.10 & 4.17 & 3.44 & n.s. & $* * *$ & $* * *$ & n.s. & $* * *$ & n.s. & n.s. \\
\hline FUTURE & 2.76 & 2.45 & 2.11 & 3.07 & 2.81 & 2.45 & 3.67 & 2.76 & n.s. & $* * *$ & $* * *$ & n.s. & $* * *$ & n.s. & n.s. \\
\hline \multicolumn{16}{|c|}{$\begin{array}{l}\text { Concern about issue over } \\
\text { next } 10 \text { years in community }\end{array}$} \\
\hline $\begin{array}{l}\text { Deteriorating water } \\
\text { infrastructure }\end{array}$ & 4.00 & 3.82 & 3.78 & 4.14 & 3.55 & 3.48 & 4.33 & 3.65 & n.s. & $* * *$ & $* * *$ & n.s. & * & n.s. & n.s. \\
\hline Water shortages & 3.62 & 3.87 & 4.12 & 3.14 & 3.58 & 3.88 & 2.88 & 3.68 & n.s. & $* * *$ & $* * *$ & n.s. & $* *$ & n.s. & n.s. \\
\hline High cost of water & 3.57 & 4.05 & 3.77 & 2.79 & 3.80 & 3.58 & 3.00 & 3.90 & n.s. & $* * *$ & $* * *$ & n.s. & * & n.s. & n.s. \\
\hline Poor water quality & 2.90 & 3.81 & 3.63 & 2.14 & 3.28 & 3.26 & 2.33 & 3.45 & n.s. & $* * *$ & $* * *$ & n.s. & $* * *$ & n.s. & n.s. \\
\hline
\end{tabular}

Note. HV iPad survey results not presented due to low sample size. ${ }^{1}$ significance based on pairwise $t$ tests comparing responses from each data source by valley. Significance test results denoted as: ${ }^{* * *} p<0.001$; ${ }^{* *} p<0.01$; ${ }^{*} p<0.05$; n.s. = not significant. SW, surface water; GW, groundwater; SL, Salt Lake; CV, Cache Valley; HV, Heber Valley; $\mathrm{HH}$, household.

water quality concern, a temporal dynamic that influences social perception. One SLV leader recounted a chemical spill that threatened drinking water quality in local groundwater supplies. A leader in another SLV city told the story of how their aquifer was contaminated by a copper mine-forcing the city to purchase $100 \%$ of their potable water from an external entity. Between the time the household surveys were conducted and the interviews, one of the SLV cities voted to switch from wells to surface water due to the perceived poor water quality of the former. These events embedded in leader and constituent memories may account for the relatively higher concern in SLV about poor water quality that had only been revealed through qualitative interview data. Table 2 also shows that SLV leaders and constituents expressed higher levels of concern about water shortages than CV or HV. In the Salt Lake City area, a "heightened" risk perception culture has evolved and been reinforced through a series of interactions between governance actors and citizens focused on motivating water conservation behaviors and flood management. This has some roots in objective biophysical conditions, since the valley communities depend much more on surface water reservoirs for their drinking water. It could also reflect the more politically liberal culture and greater awareness of and attention to environmental and sustainability issues among Salt Lake City residents and elected leaders.

Cities in CV and HV are experiencing unprecedented growth rates leading to new economic pressures and opportunities for their communities. Transitioning from single industry agriculture to multiservice urban centers has put pressure on these communities to add new infrastructure while maintaining existing infrastructure. A leader in CV said: "agriculture was king. . I I think developers are king now." Despite population growth, cities in CV and HV were still working with a relatively smaller tax base. A leader in HV told us: "Usually we're behind; [leaks] usually spring up before we think it's a problem." He explained that to optimize efficiencies, they opportunistically scheduled infrastructure projects when other state and federal agencies targeted their area, for example: "[Utah Department of Transportation] is going to replace those [culinary pipes] and next year they're going to come through and do all of Main Street, so I moved some things [like sewer projects in that area] up as priorities."

Interview data reveal how the current urban water system infrastructure reflects the historical timing of population growth and water rights allocations in each city. Under the a priori "first in time, first in right" water rights system that characterizes the American West, Salt Lake City in SLV was the colonial first 
settlement in the state and was able to secure senior water rights and build out their supply infrastructure earlier than newer cities. A leader from Salt Lake City explained: "More than any other city in the State we are in a damn good position... [going] back to Brigham Young and buying up water rights in the canyons and all over the mountains and the Jordan River. We have the lion's share of the water in this area of the Wasatch Front." At the same time, because they have some of the oldest infrastructure in Utah, Salt Lake City has a significant challenge to repair and replace their existing water supply systems. As the state's largest city, they also have a larger funding base and greater human capital resources than many other Utah municipalities to support a transition toward a more sustainable water system using new technologies to locate pipe leaks, install smart metering, and develop advanced billing applications.

There is also a type of water infrastructure that is fairly unique to Utah which is a gravity-fed, seasonal, untreated canal system historically used for farm irrigation (Salt Lake City built out without retaining much of their secondary canal system, so they depend almost completely on treated domestic water to irrigate landscaping within the city). Called a "secondary" system, use of this water for lawn use in smaller cities can substantially alleviate pressure on the culinary (drinking) water system. A leader in HV explains just how valuable this infrastructure is to their overall water situation: "we put the secondary system in because it took so much pressure off the storage and off the use of the culinary water." Leaders talked about expanding existing secondary systems, recommissioning old systems, and introducing new systems to meet new urban conservation goals-and weighing these infrastructure costs versus securing new culinary water rights. Constituents in all of our study communities were most concerned with the high costs of water (Table 2). By contrast, city leaders often expressed the view that water in Utah was underpriced when including the full cost of building infrastructure, acquiring rights, and treating water to federal standards.

\subsection{Effects of Information Sources and Community Engagement}

Because the household surveys provided information about different levels of use of different forms of media and participation in community governance activities, we can use the survey data to explore how patterns of information use and community engagement affect resident's water perceptions and concerns. Results are shown in Tables 3 and 4. Use of different sources of information were clearly related to perceptions of future water shortages, with users of each type of information expressing lower levels of agreement that future water supplies are adequate. In this sense, household survey respondents' use of information brought their views even further away from those of their leaders (listed on the left side of Table 3 as a benchmark). Higher levels of information consumption corresponded with higher levels of concern about most water issues, particularly related to concerns about deteriorating infrastructure. Interestingly, on all but the infrastructure issue, constituents who were informed by mailings from their city water provider were less likely to agree with the views of their city leaders.

Table 3

Impacts of Sources of Information About Water Issues on Household Water Perceptions and Concerns (Mean Scores)

\begin{tabular}{|c|c|c|c|c|c|c|c|c|c|c|c|c|c|c|c|c|}
\hline & \multirow[b]{3}{*}{ Leaders } & \multicolumn{14}{|c|}{$\begin{array}{l}\text { Household survey respondents use of different } \\
\text { sources of information about water issues }\end{array}$} & \\
\hline & & \multicolumn{3}{|c|}{$\begin{array}{l}\text { Mailings from } \\
\text { provider }\end{array}$} & \multicolumn{3}{|c|}{ Newspaper } & \multicolumn{3}{|c|}{ TV/radio } & \multicolumn{3}{|c|}{$\begin{array}{l}\text { Social } \\
\text { media }\end{array}$} & \multicolumn{3}{|c|}{$\begin{array}{c}\text { Friends and } \\
\text { neighbors }\end{array}$} \\
\hline & & No & Yes & & No & Yes & & No & Yes & & No & Yes & & No & Yes & \\
\hline CURRENT needs of my CITY & 4.29 & 3.31 & 3.28 & n.s. & 3.26 & 3.33 & n.s. & 3.30 & 3.30 & n.s. & 3.30 & 3.30 & n.s. & 3.29 & 3.30 & n.s. \\
\hline Water shortages & 3.34 & 3.61 & 3.84 & $* * *$ & 3.67 & 3.79 & * & 3.56 & 3.81 & $* * *$ & 3.60 & 3.81 & $* * *$ & 3.65 & 3.79 & $* *$ \\
\hline High cost of water & 3.22 & 3.82 & 4.00 & $* * *$ & 3.95 & 3.90 & n.s. & 3.81 & 3.97 & $* *$ & 3.87 & 3.93 & n.s. & 3.89 & 3.93 & n.s. \\
\hline Poor water quality & 2.56 & 3.49 & 3.57 & n.s. & 3.57 & 3.50 & n.s. & 3.43 & 3.57 & * & 3.46 & 3.56 & * & 3.53 & 3.52 & n.s. \\
\hline
\end{tabular}

Note. Significance based on pairwise $t$ tests comparing responses from each data source. Significance test results denoted as: ${ }^{* * *} p<0.001 ;{ }^{* *} p<0.01$; ${ }^{*} p<0.05 ;$ n.s. $=$ not significant. 


\section{QAGU Water Resources Research}

Table 4

Impacts of Levels of Community Engagement on Household Water Perceptions and Concerns (Mean Scores)

\begin{tabular}{|c|c|c|c|c|c|c|c|c|c|c|c|c|c|c|c|c|}
\hline & \multirow[b]{3}{*}{ Leaders } & \multicolumn{15}{|c|}{ Household survey respondent's engagement in community governance } \\
\hline & & \multicolumn{3}{|c|}{$\begin{array}{l}\text { Serve on } \\
\text { board or } \\
\text { committee }\end{array}$} & \multicolumn{3}{|c|}{$\begin{array}{l}\text { Participated } \\
\text { in civic } \\
\text { group }\end{array}$} & \multicolumn{3}{|c|}{$\begin{array}{l}\text { Contacted } \\
\text { public } \\
\text { official }\end{array}$} & \multicolumn{3}{|c|}{$\begin{array}{c}\text { Attended } \\
\text { public meeting } \\
\text { or hearing }\end{array}$} & \multicolumn{3}{|c|}{$\begin{array}{l}\text { Worked } \\
\text { with others } \\
\text { on issue }\end{array}$} \\
\hline & & No & Yes & & No & Yes & & No & Yes & & No & Yes & & No & Yes & \\
\hline CURRENT needs of my CITY & 4.29 & 3.28 & 3.59 & $* * *$ & 3.26 & 3.35 & * & 3.27 & 3.38 & * & 3.27 & 3.36 & n.s. & 3.27 & 3.39 & * \\
\hline FUTURE needs of my CITY & 3.00 & 2.63 & 2.72 & n.s. & 2.69 & 2.58 & * & 2.66 & 2.56 & n.s. & 2.66 & 2.60 & n.s. & 2.64 & 2.62 & n.s. \\
\hline Deteriorating water infrastructure & 4.10 & 3.68 & 3.69 & n.s. & 3.66 & 3.70 & n.s. & 3.64 & 3.79 & $* *$ & 3.68 & 3.70 & n.s. & 3.65 & 3.79 & $* *$ \\
\hline Water shortages & 3.34 & 3.73 & 3.63 & n.s. & 3.70 & 3.76 & n.s. & 3.68 & 3.82 & $* *$ & 3.69 & 3.77 & n.s. & 3.69 & 3.81 & $*$ \\
\hline High cost of water & 3.22 & 3.93 & 3.75 & $*$ & 3.93 & 3.91 & n.s. & 3.94 & 3.85 & n.s. & 3.95 & 3.85 & * & 3.94 & 3.85 & n.s. \\
\hline Poor water quality & 2.56 & 3.54 & 3.36 & n.s. & 3.58 & 3.47 & n.s. & 3.54 & 3.50 & n.s. & 3.57 & 3.44 & $*$ & 3.53 & 3.54 & n.s. \\
\hline
\end{tabular}

Note. Significance based on pairwise $t$ tests comparing responses from each data source. Significance test results denoted as: ${ }^{* * *} p<0.001 ;{ }^{* *} p<0.01 ;{ }^{*} p<0.05$; n.s. = not significant.

Meanwhile, residents who were more engaged in their community tended to have modestly higher levels of agreement that the current water supplies were adequate to meet the needs of their city (Table 4). This effect was strongest for those who served on government boards or committees. Engagement in community civic and governance activities was also associated with concern about various water issues, though the direction of the effect differed depending on the type of engagement. Residents who had worked with others in their community on issues and those who had contacted public officials over the last year were more likely to be concerned about water shortages and deteriorating infrastructure. By contrast, those who served on boards or committees were less likely to be concerned about high costs of water services. Similarly, people who had attended a public meeting or a hearing were less concerned with water quality and high water costs than those who did not attend such meetings.

\subsection{Leader Perceptions of Information Exchange and Community Engagement}

In the interviews with water system leaders, we solicited examples of patterns of interaction between leaders and their constituents. In this section, we explore whether elected officials and water managers received feedback in different ways, and how both groups of water system leaders perceived the actions and perceptions of their constituents.

The elected officials (mayors and city councilpersons) interviewed for this study mentioned a number of ways in which they interacted with the public. Some of the responses included meeting legal requirements mandated by State agencies to inform the public, for example, through television ads and water quality reports. Some of the larger cities have neighborhood councils or meetings where residents could voice their opinion directly to their representatives. One elected official from the CV hesitated to reach out to the public too much, saying, "... We try not to cry to the public and ask them to do things on a regular basis because then sometimes they will lose their commitment, thinking that's all you ever do. But their response was quite good, and I would say overall we have a very responsible community when it comes to water conservation." Regarding a preference for types of interventions, an elected official in the SLV said: "I'm a little bit more inclined to use technology or the free market to solve these problems. . .l'm a little reluctant to use government regulations unless it's a drought."

Elected officials also described how they received information from the public. Many said that they did not receive complaints about flooding except for occasional stormwater events. Others mentioned that public outcry occured sporadically and around development issues: "This one neighbor of mine and that went up to the Mayor, shaking her finger at him and said, 'You better not let any more development here because we don't have any water!'" (elected official, CV). Others said they don't receive direct messages from the public: "I don't think we're getting pushed a lot from the community; I think that they figure we're doing what we're supposed to be doing" (elected official, HV), while others said they received indirect messages in the form of who and what gets voted on (elected officials, SLV). 
Water managers (public utilities staff, engineers, and other city staff) described their interactions with the public in the following ways: mass media (e.g., social media, brochures, and websites), letters to the newspaper, direct email, face-to-face interactions through open city hall meetings, public speaking, "being out and about," public education programs, and demonstration gardens. They also felt they signaled water conservation messages to the public through tiered grade rate structures, coding, zoning, permitting, metering, and billing. A water manager from SLV wondered if their messages were reaching residents equally:

I want to take a hard look at our outreach programs because they've been around a long time and they haven't changed... One thing I've noticed about our watershed protection education program, it has been visible to those who recreate in those mountains. There's only a certain segment of our community that is being exposed to that.

Meanwhile, both water managers and elected officials sometimes thought the public tended to be reactive. A public utilities staff member from CV said: "Life is good. So, when we go in and start tearing up a canal or a road or a waterline in front of people's houses, until we're out there getting started, they could care less. The minute we start, it's 'you idiots, what are you thinking?'"

Water managers received information from the public in a variety of ways. One city established a public advisory committee that tracked water use on a monthly basis based on rates and meter reads. Using this information, one water manager from SLV remarked: "When the weather is rainy, water use drops. Educated people turn off the sprinklers when it's raining! So, people are listening to the conservation message." Another city used trial and error:

If we run short, we will ask [agricultural users] to alternate and cut back. We tried various ways of rationing water and monitoring like letting people with odd house numbers water one day and even numbers the next. We found we used more water that way because the people thought, "Well I'm not going to have the water tomorrow so I gotta soak it up real good today," even if it was raining because I won't have the water tomorrow. (city staff, HV)

One water manager from CV had seen a difference between projects with and without public involvement, and preferred the former: "We've had projects in the past where's there's very little public involvement, and the project was derailed midway through, and we did the same project years later with much more public involvement, and it went smoothly." A water manager in CV lamented limited public engagement, commenting: "I would like to see more involvement, percentage-wise, in a given area." Another elected official in SLV pointed out that modern community engagement doesn't always happen in person saying:

I've noticed kind of a community rallying, you know, people say, "Hey, it's not even June, you don't have to water yet," on social media they'll kind of urge each other, "Let's not have a race to see who can have the greenest lawn just yet."

We did not find evidence to support the idea that information exchange between constituents and leaders or citizen engagement in water issues varied by place, although an elected official from SLV observed pockets of engagement within cities based on socio-demographic patterns: "The University is in our district. It's well-educated, fairly well-to-do. So, people are engaged."

\section{Discussion and Conclusions}

In this study, we found consistent differences between the perceptions and concerns of constituents and their water system leaders. Using a mixed method approach and multiple data sets of Utah leaders and their constituents, we found that constituents consistently showed higher concern about future water shortages and the high cost of water services. Meanwhile, leaders demonstrated the most concern for deteriorating water infrastructure, and more confidence in the current and future availability of water to meet the needs of their cities. 
We found strong evidence in our study area for direct and intentional pathways of influence in urban water governance. In other words, information exchange and engagement between leaders and constituents were stronger predictors of water issue alignment than hydrologic differences and geography. This finding suggests that the density of opportunities for citizen engagement in local water decisions can reduce a perception and concern gap between leaders and city residents. In our interviews, most leaders recognized that they could do more to engage constituents in water issues in two-way communication, and noted that public participation was not equally distributed across social groups in their communities. Our work also produced examples of past city water projects or initiatives that had been derailed because of misalignment between the goals and priorities of leaders and constituents. Innovative transitions to sustainable local water governance are likely to require greater consensus between leaders and constituents, and providing opportunities for information exchange and engagement may help address them. Interestingly, when alignment was found in a city, it was most common for citizens who were most engaged in local governance to absorb or agree with the perspectives of water system leaders. We found less evidence that citizen involvement transformed the priorities of water system leaders to better reflect their constituents.

Differences in perceptions and concerns between valleys and cities seemed to be associated with city size and stage of urban growth and development. For example, leaders in the most populous and established municipality (Salt Lake City) expressed different concerns and challenges than leaders of newly established and rapidly growing communities. These differences likely reflect a mix of factors: (a) the seniority of their water rights, (b) the scale of their operations-which influences economies of service provision, division of labor among staff, etc., (c) the age and needs of their existing water infrastructure, (d) the degree to which their irrigation canal infrastructure had already been replaced by culinary domestic water systems, and (e) the role that developers play in local politics.

Future research on socio-hydrological systems should not ignore the importance of social structure in influencing perceptions, how flows of information are constrained or enabled, and public experience of involvement with water issues. Our findings that perceptions and concerns vary based on social roles within a community are consistent with previous work that observed gaps between leader and public perceptions on a number of issues. Similar to comparisons of lay and expert opinions on climate change risk to ecosystems (Lazo et al., 2000) and nuclear waste and nuclear power (Sjoberg, 1999), we also found that experts perceived slightly lower risks, in this case, from inadequate water supplies in the present and future. Others (Crowe et al., 2015) found differences in how Illinois and Kentucky constituents perceived shale development vis-à-vis leaders although leaders assumed that constituents shared their beliefs. In our study, interviews indicate that leaders in Utah might be less certain that their constituents are on the same page in terms of water issues.

Responses support the idea of community response to risk (Flint \& Luloff, 2005) in that the interviews revealed the cultural, political, economic, and built environment structures that define risk perception within localized socio-hydrological contexts. For example, one elected official from CV explained what they saw as a lack of constituent concern because of the unique cultural context in Utah, saying "What the [LDS] church does is take a lot of their time, time that might have otherwise gone into community development or might have gone into community activism... I think we're just tired." An elected official from SLV explained low citizen involvement because of the lack of effective political structure that would allow concerns to translate into real action on water issues: "I think residents being vocal is totally meaningless until there are real policy tools available. Then people can count on and trust that their efforts will [result in a tangible outcome]." A water manager from CV explained the sentiment in economic terms: "They just say, 'well, if I can get food on the table and keep the electricity on, that's all I can care about right now.'" On the other hand, a water manager from HV attributed a transition to a more concerned public to the built environment and changing demographics:

I think that we see a change in the environmental ethics simply because a lot of the people are moving here because they think it is a better environment... less congestion on the streets, less pollution, cleaner water, easy access to the recreation whether it be skiing or boating or hunting or fishing or camping, it's 15 min away.

Our results suggest that future socio-hydrology models should explore ways to expand representation of different types of social actors (leaders versus residents), and to represent their access to information about, 
and their perceptions and experiences of water system conditions as mediated by characteristics of their natural, built, and social structure. We found that patterns of interaction between leaders and their constituents played important roles in urban water management as much as, if not more so, than either the temporal or spatial dynamics.

Finally, our project supports recommendations for better integrating community actors into studies of water risk for better policies and communication (Paveglio et al., 2016). There is growing attention to the importance of understanding differences between organizational and institutional actors, who often control water system infrastructure and shape incentives through policies and programs, and individual water users, whose actions are the building blocks of water system outcomes. Socio-hydrology models that are better able to capture situations where perceptions and expectations of leaders and water users are misaligned may be better able to predict or explain failures to successfully adapt to changing environmental conditions (Scott, 2011; Yu et al., 2017). Acknowledging differences in perception, information, and experience between different actors can also identify situations with a high potential for conflict, where some types of actors might attempt to block action set forth by others with differing priorities.

Future studies using longitudinal data could help reveal temporal and path-dependent dynamics that influence the evolution of socio-hydrological systems. Based on our initial findings, we would expect legacies associated with extreme droughts, floods, or water quality events, patterns of water rights acquisition, the timing of infrastructure construction and population growth, and thresholds associated infrastructure economies of scale to all be important in shaping when and how citizens and leaders perceive water problems as serious enough to warrant making fundamental changes in their urban water systems.

\section{Acknowledgments}

This research was supported by NSF EPSCoR grant IIA 1208732 awarded to Utah State University, as part of the State of Utah EPSCoR Research Infrastructure Improvement Award. Utah State University support for researchers was not tied to Koch Foundation funding. Any opinions, findings, and conclusions or recommendations expressed are those of the author(s) and do not necessarily reflect the views of the National Science Foundation. We would like to thank the interviewees and survey respondents without whom this project would not be possible. Deidentified household survey data and resident survey data can both be accessed through Hydroshare at http://www.hydroshare.org/resource/ 72ab49b468bc427fa2024b5b716d3103 (Utah's Water Future-2014 Household Survey) and http://www.hydroshare. org/resource/a2cde5-

c64087408886aa3b8360b2cbb5 (UTAH WATER SURVEY: Perceptions and Concerns about Water Issues).

\section{References}

Anderson, B. J., \& Theodori, G. L. (2009). Local leaders' perceptions of energy development in the Barnett shale. Southern Rural Sociology, 24(1), 113-129.

Betsill, M. M., \& Bulkeley, H. (2006). Cities and the multilevel governance of global climate change. Global Governance: A Review of Multilateralism and International Organizations, 12(2), 141-159.

Canter, L. W., Nelson, D., \& Everett, J. (1993). Public perception of water quality risks-influencing factors and enhancement opportunities. Journal of Environmental Systems, 22, 163-163. https://doi.org/10.2190/93D9-JF0N-EEF8-W4PW

Chang, H., Thiers, P., Netusil, N. R., Yeakley, J. A., Rollwagen-Bollens, G., Bollens, S. M., et al. (2014). Relationships between environmental governance and water quality in a growing metropolitan area of the pacific northwest, USA. Hydrology and Earth System Sciences, 18(4), 1383. https://doi.org/10.5194/hess-18-1383-2014

Chen, X., Wang, D., Tian, F., \& Sivapalan, M. (2016). From channelization to restoration: Sociohydrologic modeling with changing community preferences in the Kissimmee River Basin, Florida. Water Resources Research, 52, 1227-1244. https://doi.org/10.1002/2015WR018194

Coppock, M. H., \& Brown, R. R. (2007). Advancing sustainable water futures for Melbourne: Analysis of expert opinion on structural and non-structural approaches. Water Practice and Technology, 2(2), wpt2007054. https://doi.org/10.2166/wpt.2007.054

Crowe, J., Silva, T., Ceresola, R. G., Buday, A., \& Leonard, C. (2015). Differences in public perceptions and leaders' perceptions on hydraulic fracturing and shale development. Sociological Perspectives, 58(3), 441-463. http://doi.org/10.1177/0731121414567355

de França Doria, M. (2010). Factors influencing public perception of drinking water quality. Water Policy, 12(1), 1-19. http://doi.org/10. 2166/wp.2009.051

Denzin, N. K., \& Lincoln, Y. S. (2011). The Sage handbook of qualitative research. Newcastle upon Tyne, UK: Sage.

di Baldassarre, G. D., Viglione, A., Carr, G., Kuil, L., Salinas, J. L., \& Blöschl, G. (2013). Socio-hydrology: Conceptualising human-flood interactions. Hydrology and Earth System Sciences, 17(8), 3295. https://doi.org/10.5194/hess-17-3295-2013

Elshafei, Y., Sivapalan, M., Tonts, M., \& Hipsey, M. R. (2014). A prototype framework for models of socio-hydrology: identification of key feedback loops and parameterisation approach. Hydrology and Earth Systems Sciences, 18, 2141-2166. http://doi.org/10.5194/hess-18-21412014

Endter-Wada, J., Selfa, T., \& Welsh, L. W. (2009). Hydrologic interdependencies and human cooperation: The process of adapting to droughts. Weather, Climate, and Society, 1(1), 54-70. http://doi.org/10.1175/2009WCAS1009.1

Endter-Wada, J., Hall, A., Jackson-Smith, D., \& Flint, C. (2015). Utah's water future: Perspectives on water issues in Utah's Wasatch Range Metropolitan Area. Summary report of overall findings from the iUTAH 2014 household survey (iUTAH technical report). Retrieved from http:// data/iutahepscor.org/mdf/reports/SummaryReport-iUTAH2014HouseholdSurvey.pdf

Fitchen, J. M., Heath, J. S., \& Fessenden-Raden, J. (1987). Risk perception in community context: A case study. In B. B. Johnson \& V. T. Covello (Eds.), The social and cultural construction of risk: Essays on risk selection and perception (pp. 31-54). Boston, MA: D. Reidel.

Flint, C. G., Dai, X., Jackson-Smith, D., Endter-Wada, J., Yeo, S. K., Hale, R., et al. (2017). Social and geographic contexts of water concerns in Utah. Society \& Natural Resources, 30(8), 885-902. http://doi.org/10.1080/08941920.2016.1264653

Flint, C. G., \& Luloff, A. (2005). Natural resource-based communities, risk, and disaster: An intersection of theories. Society and Natural Resources, 18(5), 399-412. https://doi.org/10.1080/08941920590924747

Haeffner, M., Galvin, K., \& Vázquez, A. E. G. (2016). Urban water development in La Paz, Mexico 1960-present: A hydrosocial perspective. Water History, 9, 169-187. https://doi.org/10.1007/s12685-016-0180-z

Hale, R. L., Armstrong, A., Baker, M. A., Bedingfield, S., Betts, D., Buahin, C., et al. (2015). iSAW: Integrating structure, actors, and water to study socio-hydro-ecological systems. Earth's Future, 3(3), 110-132. https://doi.org/10.1002/2014EF000295

Head, B. W. (2014). Managing urban water crises: Adaptive policy responses to drought and flood in Southeast Queensland, Australia. Ecology and Society, 19(2), 33. https://doi.org/10.5751/ES-06414-190233 
Hess, D. J., Wold, C. A., Hunter, E., Nay, J., Worland, S., Gilligan, J., et al. (2016). Drought, risk, and institutional politics in the American southwest. Sociological Forum, 31(51), 807-827. https://doi.org/10.1111/socf.12274

Hughes, S., Pincetl, S., \& Boone, C. (2013). Triple exposure: Regulatory, climatic, and political drivers of water management changes in the city of Los Angeles. Cities, 32, 51-59. https://doi.org/10.1016/j.cities.2013.02.007

Jackson-Smith, D., Dolan, M., Holyoak, G., Flint, C. G., Trentelman, C. K., Thomas, B., et al. (2016a). Effectiveness of the drop-off/pick-up survey methodology in different neighborhood types. Journal of Rural Social Sciences, 31(3), 35-66.

Jackson-Smith, D., \& Flint, C. (2016). Utah's water future: 2014 household survey. HydroShare. Retrieved from http://www.hydroshare.org/ resource/72ab49b468bc427fa2024b5b716d3103

Jackson-Smith, D., \& Flint, C. (2017). Utah water survey: Perceptions and concerns about water issues. HydroShare. Retrieved from http:// www.hydroshare.org/resource/a2cde5c64087408886aa3b8360b2cbb5

Jackson-Smith, D., Stoker, P., Buchert, M., Endter-Wada, J., Licon, C., Cannon, M., et al. (2016b). Differentiating urban forms: A neighborhood typology for understanding urban water systems. Cities and the Environment (CATE), 9(1), 5.

Johnson, R. B., Onwuegbuzie, A. J., \& Turner, L. A. (2007). Toward a definition of mixed methods research. Journal of Mixed Methods Research, 1(2), 112-133. https://doi.org/10.1177/1558689806298224

Jones, A. S., Horsburgh, J. S., Jackson-Smith, D., Ramírez, M., Flint, C. G., \& Caraballo, J. (2016). A web-based, interactive visualization tool for social environmental survey data. Environmental Modelling \& Software, 84, 412-426. https://doi.org/10.1016/j.envsoft.2016.07.013

Klandermans, B., \& Staggenborg, S. (2002). Methods of social movement research (Vol. 16). Minneapolis, MN: University of Minnesota Press.

Lazo, J. K., Kinnell, J. C., \& Fisher, A. (2000). Expert and layperson perceptions of ecosystem risk. Risk Analysis, 20(2), 179-194. https://doi. org/10.1111/0272-4332.202019

Liu, Y., Tian, F., Hu, H., \& Sivapalan, M. (2014). Sociohydrologic perspectives of the coevolution of humans and water in the Tarim River basin, Western China: The Taiji-Tire model. Hydrology and Earth System Sciences, 18, 1289-1303. https://doi.org/10.5194/hess-18-12892014

Logan, H. R., Whaley, R. B., \& Crowder, K. (1997). The character and consequences of growth regimes: An assessment of 20 years of research. Urban Affairs Review, 32(5), 603-630.

Maupin, M. A., Kenny, J. F., Hutson, S. S., Lovelace, J. K., Barber, N. L., \& Linsey, K. S. (2014). Estimated use of water in the United States in 2010 (U.S. Geol. Surv. Circ. 1405, 56 p.). Reston, VA: U.S. Geological Survey. https://doi.org/10.3133/cir1405

Moss, T., \& Newig, J. (2010). Multilevel water governance and problems of scale: Setting the stage for a broader debate. Environmental Management, 46, 1-6. https://doi.org/10.1007/s00267-010-9531-1

Munger, F., \& Houghton, A. (1965). Politics and organization in water resource administration: A comparative study of decisions. Water Resources Research, 1(3), 337-347. https://doi.org/10.1029/WR001i003p00337

O'Connor, R. E., Yarnal, B., Dow, K., Jocoy, C. L., \& Carbone, G. J. (2005). Feeling at risk matters: Water managers and the decision to use forecasts. Risk Analysis, 25(5), 1265-1275. https://doi.org/10.1111/j.1539-6924.2005.00675.x

Pande, S., \& Sivapalan, M. (2017). Progress in socio-hydrology: A meta-analysis of challenges and opportunities. Wiley Interdisciplinary Reviews: Water, 4(4), e1193. https://doi.org/10.1002/wat2.1193

Paveglio, T. B., Boyd, A. D., \& Carroll, M. S. (2016). Re-conceptualizing community in risk research. Journal of Risk Research, 1-21. https://doi. org/10.1080/13669877.2015.1121908

Po, M., Nancarrow, B. E., \& Kaercher, J. D. (2003). Literature review of factors influencing public perceptions of water reuse (CSIRO Land and Water Tech. Rep. 54/03). Canberra, Australia: Commonwealth Scientific and Industrial Research Organisation.

Rinaudo, J. D., \& Garin, P. (2005). The benefits of combining lay and expert input for water-management planning at the watershed level. Water Policy, 7(3), 279-293.

Scott, C. A. (2011). The water-energy-climate nexus: resources and policy outlook for aquifers in Mexico. Water Resources Research, 47, W00L04. https://doi.org/10.1029/2011WR010805

Sherren, K., Beckley, T. M., Greenland-Smith, S., \& Comeau, L. (2017). How provincial and local discourses aligned against the prospect of dam removal in New Brunswick, Canada. Water Alternatives, 10(3), 697-723.

Sivapalan, M., Konar, M., Srinivasan, V., Chhatre, A., Wutich, A., Scott, C. A., et al. (2014). Socio-hydrology: Use-inspired water sustainability science for the Anthropocene. Earth's Future, (2), 225-230. https://doi.org/10.1002/2013EF000164

Sivapalan, M., Savenije, H. H. G., \& Blöschl, G. (2012). Socio-hydrology: A new science of people and water. Hydrological Processes, 26(8), 1270-1276. https://doi.org/10.1002/hyp.8426

Sjoberg, L. (1999). Risk perception by the public and by experts: A dilemma in risk management. Human Ecology Review, 6(2), 1-9.

Susskind, L. (2013). Water and democracy: New roles for civil society in water governance. International Journal of Water Resources Development, 29(4), 666-677. https://doi.org/10.1080/07900627.2013.781914

Treuer, G., Koebele, E., Deslatte, A., Ernst, K., Garcia, M., \& Manago, K. (2017). A narrative method for analyzing transitions in urban wate management: The case of the Miami-Dade water and sewer department. Water Resources Research, 53, 891-908. https://doi.org/10. 1002/2016WR019658

United States Geological Survey (USGS). (2010). Water use data for Utah. Retrieved from https://waterdata.usgs.gov/ut/nwis/water_use?format $=$ html_table\&rdb_compression $=$ file\&wu_area $=$ County\&wu_year $=2010 \& w u \_c o u n t y=005 \% 2 C 035 \% 2 C 051 \& w u \_c a t e g o r y-$ ALL\%2CPS\&wu_county_nms=Cache\%2BCounty\%252CSalt\%2BLake\%2BCounty\%252CWasatch\%2BCounty\&wu_category_nms=ALL\%2BCategories-\%252CPublic\%2BSupply, accessed 28 May 2017

Utah Department of Environmental Quality (2016). DWQ's 2016 final integrated report water quality assessment program. Retrieved from https://deq.utah.gov/ProgramsServices/programs/water/monitoring-reporting/assessment/currentIR2016.htm, accessed 6 October 2017

Yu, D. J., Sangwan, N., Sung, K., Chen, X., \& Merwade, V. (2017). Incorporating institutions and collective action into a sociohydrological model of flood resilience. Water Resources Research, 53, 1336-1353. https://doi.org/10.1002/2016WR019746 